\title{
ELECTROCARDIOGRAPHIC DIAGNOSIS OF RIGHT VENTRICULAR HYPERTROPHY IN INFANCY AND CHILDHOOD
}

\author{
BY \\ ARTHUR HOLLMAN* \\ From the Montreal Childrens Hospital and the Department of Pediatrics, McGill University \\ Received July 21, 1957
}

The demonstration of ventricular hypertrophy is a routine step in the diagnosis of congenital heart disease and it is important that the accuracy of the electrocardiographic criteria for the diagnosis of ventricular hypertrophy should be known and their reliability established. Such criteria have been defined and studied extensively in adults, but less so in infants and children.

In view of the particular difficulties attending the diagnosis of right ventricular hypertrophy (R.V.H.) in the first few years of life, a particular study of this subject has been made. Criteria will be presented for this diagnosis from one month to fifteen years of age and their usefulness determined by applying them to a series of cases of congenital heart disease with autopsy proof of hypertrophy of the right ventricle. In assessing the value of the electrocardiogram in detecting ventricular hypertrophy it is believed that autopsy proof is highly desirable, since clinical and radiological findings are not necessarily reliable either in detecting hypertrophy or in distinguishing which ventricle is affected.

\section{Previous Views of Diagnostic Criteria}

Gordon and Goldberg (1951) concluded that the diagnosis of right heart strain was very difficult under the age of three years. Schaffer (1950) reported on five infants and found that serial tracings with a sequence of increasing right ventricular preponderance were valuable evidence of R.V.H. Sokolow and Edgar (1950) found that 28 out of 29 autopsy cases of R.V.H. had electrocardiographic evidence for this: but the majority of their cases were children, 14 being under the age of one year and several of their criteria would indicate the presence of R.V.H. even in normal infants and children. Goodwin (1952) examined 36 cases with presumed R.V.H., aged 3-14 years, and found the $\mathrm{R} / \mathrm{S}$ ratio in $\mathrm{V} 1$ to be greater than 1.0 in 80 per cent of his cases and considered this to be an important diagnostic sign. This ratio may however be over 1.0 in normal children up to the age of 10 years. Veasey and Adams (1952) modified the criteria of Sokolow and Lyon (1949) for use in children: among cases of congenital heart disease they found that the R/S ratios in V1 and V5 were the most reliable indication of ventricular hypertrophy but it is not clear what values for the criteria they considered abnormal at various ages. Cabrera and Monroy (1952) distinguished between the pattern of " systolic overloading" with a high $R$ and inverted $T$ in V1, and " diastolic overloading" with right bundle-branch block. Ziegler (1956) found a direct correlation between the incidence of positive $T$ waves in the right præcordial leads and the rise of right ventricular mean pressure.

\section{Determination of the Criteria}

In infancy and early childhood the right ventricle is relatively thick compared with the left, the ratio between the two at birth being 6 to 7, compared with 1 to 2 in adult life. After the age of

* Work undertaken while Bilton Pollard Travelling Fellow of University College Hospital Medical School. Present address : Hammersmith Hospital, London, W.12. 
three months the left ventricle starts to become dominant and by the age of 6 years the normal left ventricular dominance of adult life is largely established, but a slow change occurs up to the time of puberty. This physiological right ventricular dominance gives rise to electrocardiographic changes that are similar to those of right ventricular hypertrophy in adult life. The R.V. dominance at birth and its subsequent gradual involution are clearly shown in the R/S ratios in leads V1, V5, and aVR at different ages (Fig. 1). The R/S in V1 averages 3.7 from one to three months of age, falling

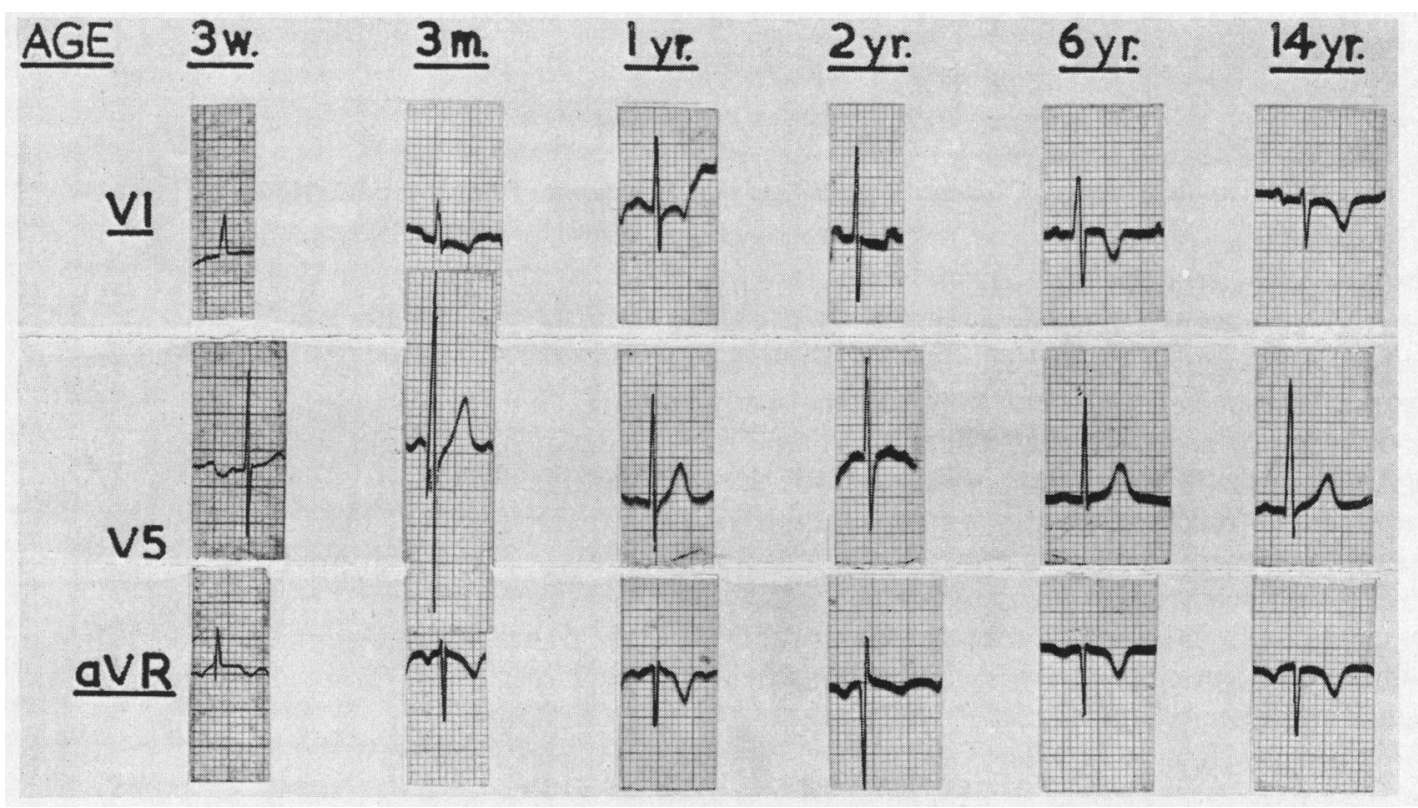

Fig. 1.-Representative normal electrocardiograms to show resolution of physiological right ventricular preponderance with age. Note that a dominant $R$ in aVR does not occur over one month.

to 1.7 at one year and to 0.6 by five years: corresponding figures for V5 are $0.8,2.9$, and 7.8 (Gros et al., 1951). It is therefore clear that specific numerical criteria must be used in order to distinguish a pathological from a physiological degree of R.V.H. at different ages.

Criteria were therefore formulated for use between the ages of one month and fifteen years, and these are presented in Table I. They were determined as follows. The various features of right ventricular hypertrophy were listed and then for each feature a numerical value was assigned which lay outside the normal value at a particular age. For example, the $R / S$ ratio in lead V1 never exceeds 4.0 from four to eleven months of age, and it was therefore reasoned that when it equalled or exceeded 4.5 it could be taken as evidence of R.V.H. Similar reasoning was applied to all the other criteria. The normal values were obtained from several excellent publications on the cardiograms in normal children by various authors with a total experience of over 700 cases (Alimurung et al., 1951; Gros et al., 1951; Richman and Master, 1951; Schaffer et al., 1950; Switzer and Besoain, 1950; Tudbury and Atkinson, 1950; Yu et al., 1951; and Ziegler, 1951).

During the first five years of life there is a rapid change in the $\mathrm{R} / \mathrm{S}$ ratio in leads V1 and V5 (Fig. 1) and this made it necessary to subdivide this age group closely in respect of these criteria.

Criteria were not determined for the first month of life since there is a rapid change in the cardiogram in this period. There would appear to be good evidence that the relative and actual amplitudes of the præcordial $\mathbf{R}$ and $\mathrm{S}$ waves are unaltered when right bundle-branch block is present (Barker and Valencia, 1949; Laham et al., 1951; Myers et al., 1948; and Kroop et al., 1951) and cases with such block are therefore not excluded from being judged by these criteria, with the exception of the intrinsicoid deflection time in V1. 
Criteria were worked out for the actual amplitudes (as opposed to the ratio) of the $\mathbf{R}$ and $\mathbf{S}$ waves in V1, V5, and aVR. They were not found to help in diagnosis and may in addition be misleading if the electrode placement is not precise since very high voltages may normally occur in V3 in normal children. For these reasons the use of these criteria is not recommended.

Material and Methods. Preserved hearts were available from 42 cases of congenital heart disease on whom cardiograms had been taken. A decision on the presence and degree of myocardial hypertrophy was made in each case by comparison with a normal preserved heart from a child of the same age. Twenty-nine of the hearts were found to have hypertrophy of the right ventricle only and these cases form the material of this report.

Age Groups. 1-3 months, 6 cases; 4-11 months, 13; 1-5 years, 6; 6-15 years, 4 . Thus 19 cases $(66 \%)$ were under the age of one year and therefore in an age group where the diagnosis of an abnormal degree of R.V.H. might be expected to be the most difficult. The most frequent anomalies were Fallot's tetralogy in 10 cases, transposition in 5, and total anomalous venous drainage in 3 cases.

\section{TABLE I}

Criteria for the Diagnosis of Right Ventricular Hypertrophy from One Month to Fifteen YEARS OF AGE

(1) Presence of a Q wave in V1.

(2) Onset of intrinsicoid deflection in V1 delayed to 0.04 sec. or more in the absence of right bundle-branch block.

(3) $\mathrm{R} / \mathrm{S}$ or $\mathrm{R} / \mathrm{Q}$ in aVR of over 1.0 .

(4) P wave of $3 \mathrm{~mm}$. or more in lead II, or $2.5 \mathrm{~mm}$. or more in any other lead.

(5) Electrical axis of over $+120^{\circ}$.

(6) $\mathrm{R} / \mathrm{S}$ in V1 and V5 as below.

\begin{tabular}{lll|c|c|c|c|c|l}
\hline & & & $1-3$ months & $4-11$ months & $1-2$ years & $3-5$ years & $6-15$ years & \\
\hline R/S V1 &.. &.. & 7.0 & 4.5 & 2.5 & 2.0 & 1.5 & or more \\
\hline R/S V5 &.. &.. & 0.5 & 0.7 & 0.8 & 0.9 & 0.9 & or less \\
\hline
\end{tabular}

Analysis. The criteria for the diagnosis of R.V.H. as shown in Table I were applied to the findings in each case and the results tabulated and analysed. The cardiogram consisted of the standard and augmented unipolar limb leads and leads V1, V3, and V5 except for three cases in which the aV leads were not taken.

\section{RESULTS}

The frequency with which the various criteria were satisfied is shown in Table II. Of the 29 cases there were $25(86 \%)$ in whom two or more criteria were present thus permitting a definite diagnosis of right ventricular hypertrophy to be made. Of the 4 remaining cases one criterion was satisfied in each of three cases and these are classed as having probable evidence of R.V.H. Details of these four are as follows. Case 9 , aged 4 months, had tricuspid stenosis and pulmonary atresia with a normal thickness of compact myocardium but with very thick trabeculae in the right ventricle, and the R/S ratio in V5 was abnormally low. Case 5, aged 2 months, with Eisenmenger's complex, had a $P$ wave in V3 of $3 \mathrm{~mm}$. as the only abnormal feature. Case 20, aged 1 year, with Fallot's tetralogy had an abnormal electrical axis of $+160^{\circ}$. The $\mathrm{R} / \mathrm{S}$ ratio in $\mathrm{V} 1$ of $2 \cdot 3$ was close to the criterion value of $2 \cdot 5$. The fourth, Case 6 , aged 3 months had complete transposition but no abnormal features apart from left axis deviation (axis $-30^{\circ}$ ): this represents the only complete failure of diagnosis. 
TABLE II

The Frequency with which the Various Criteria were Satisfied in a Series of 29 Cases with Right Ventricular HyPERTROPHY CONFIRMEd AT AUTOPSY

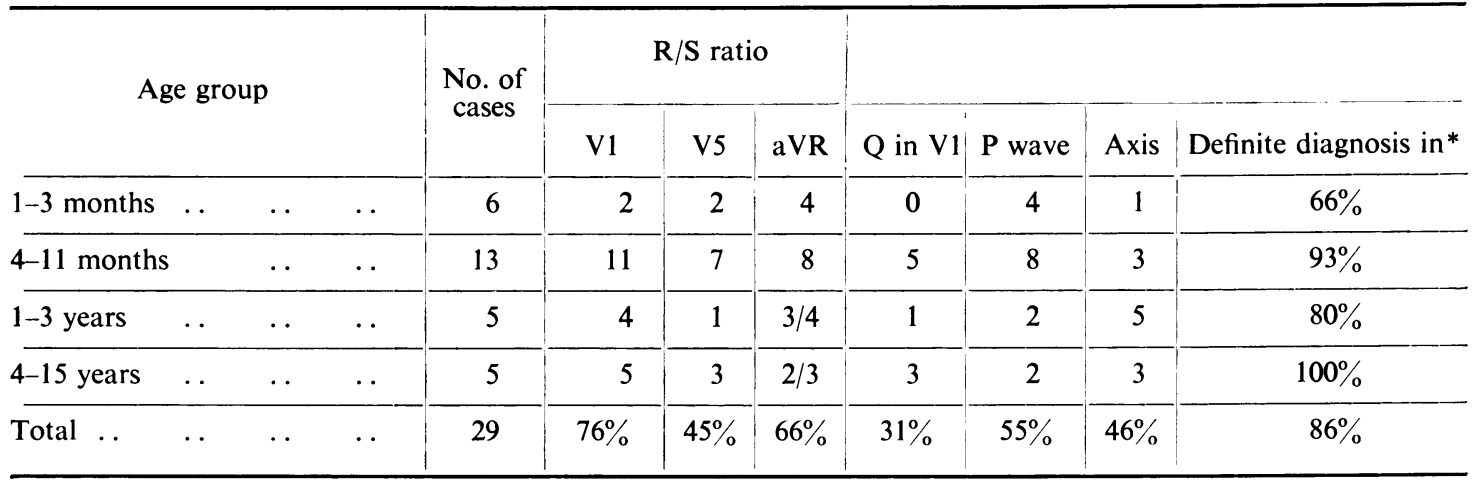

* i.e. two or more criteria satisfied.

\section{Discussion OF CRITERIA AND RESUlts}

The evidence presented in the preceding section has shown that 86 per cent of a series of autopsy proven cases of right ventricular hypertrophy had certain evidence of such hypertrophy when using the criteria shown in Table I and that a further 10 per cent had probable evidence of R.V.H. Since these criteria were formulated on the basis of extensive studies on normal infants and children by various authors it is likely that they are reliable in differentiating pathological from physiological hypertrophy. Errors of diagnosis from their use may be in the direction of classing a case of R.V.H. as being normal - as with lead V1 of Case 20-rather than of making a false diagnosis of R.V.H. in a normal subject. This high incidence of correct diagnosis might be related to the fact that all the cases except two had considerable hypertrophy at autopsy, although a definite diagnosis was in fact made in these two cases also.

Influence of Age. As expected diagnosis was least successful in the age group one to three months where a certain diagnosis was made in only 4 of the 6 cases with a probable diagnosis in a further one. A curious finding, in contrast to the other age groups (see Table II), was the fact that the $\mathrm{R} / \mathrm{S}$ ratio in leads $\mathrm{V} 1$ and V5 was abnormal in only a third and strictly normal in the remainder. In this age group the $R / S$ in aVR and the $P$ wave were the most commonly satisfied criteria.

The various criteria will now be considered individually.

$R / S$ Ratio in $V 1$. This criterion was satisfied more frequently than any other, being present in 76 per cent of cases. However in 7 per cent of normal infants aged one to three months Ziegler (1951) has found this ratio to have a value of infinity. The criterion should not therefore be used by itself as evidence of R.V.H. in this age group. The algebraic sum of $R+S$, as introduced by Alimurung et al. (1951), overcomes this difficulty and may prove more useful at this age.

$R / S$ Ratio in V5. Although satisfied in only 45 per cent of the total, this lead has a particular value in the very young. As already mentioned the use of $\mathrm{R} / \mathrm{S} \mathrm{V} 1$ from one to three months is restricted by the fact that the normal and pathological ratios have a slight overlap. This objection does not apply to the ratio in V5 where figures far removed from the normal may be obtained. (Fig. 2 and 3).

$Q$ Wave in V1. This was found in 31 per cent. It was never the sole abnormality in this lead and when it was present there were always abnormalities in other leads too. It thus appears to be a late sign of R.V.H. but does have the advantage of being an unequivocal abnormality at all ages.

Intrinsicoid Deflection in V1. This was delayed in 7 of the 20 cases $(35 \%)$ without right bundlebranch block. All the cases had other evidence of R.V.H. in V1 and thus this criterion proved of no 


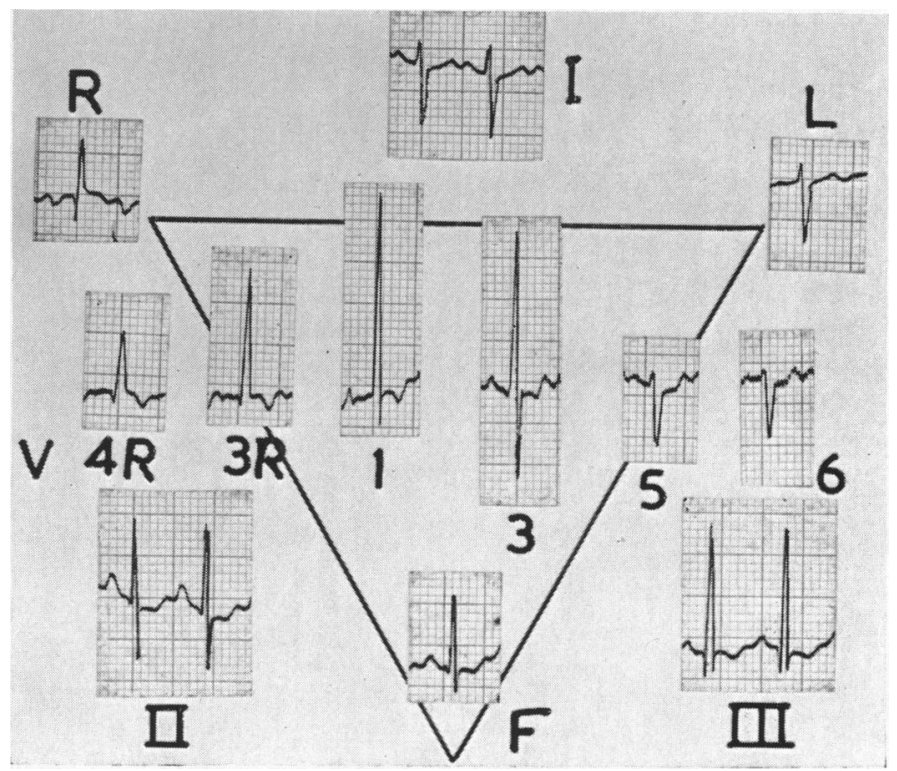

FIG. 2.-To show the particular value of lead V5 in the young infant. The R/S in V5 of 0.2 differs greatly, by over 300 per cent from the criterion value of 0.7 , while in V1 the $R / S$ ratio of 6.0 is only 30 per cent greater than the criterion of $4 \cdot 5$. Case of congenital mitral stenosis, aged 4 months with considerable R.V.H. (autopsy proof).

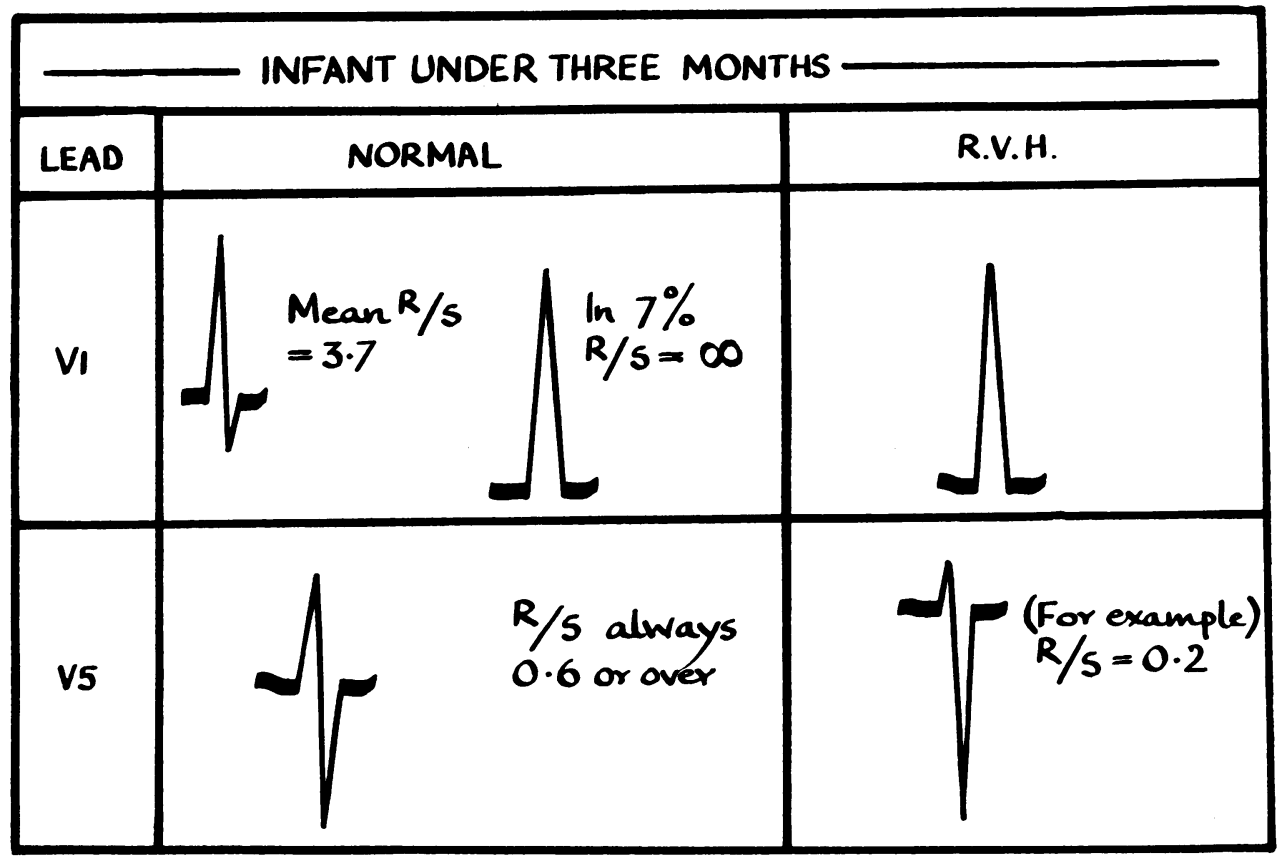

FIG. 3.-In infants under the age of 3 months the $R / S$ ratio in V1 is normally quite high and in 7 per cent it reaches infinity. Thus, in contrast with adults, there is relatively little change from the normal to the abnormal pattern. In lead V5 however there is ample scope for change to an abnormal pattern. 


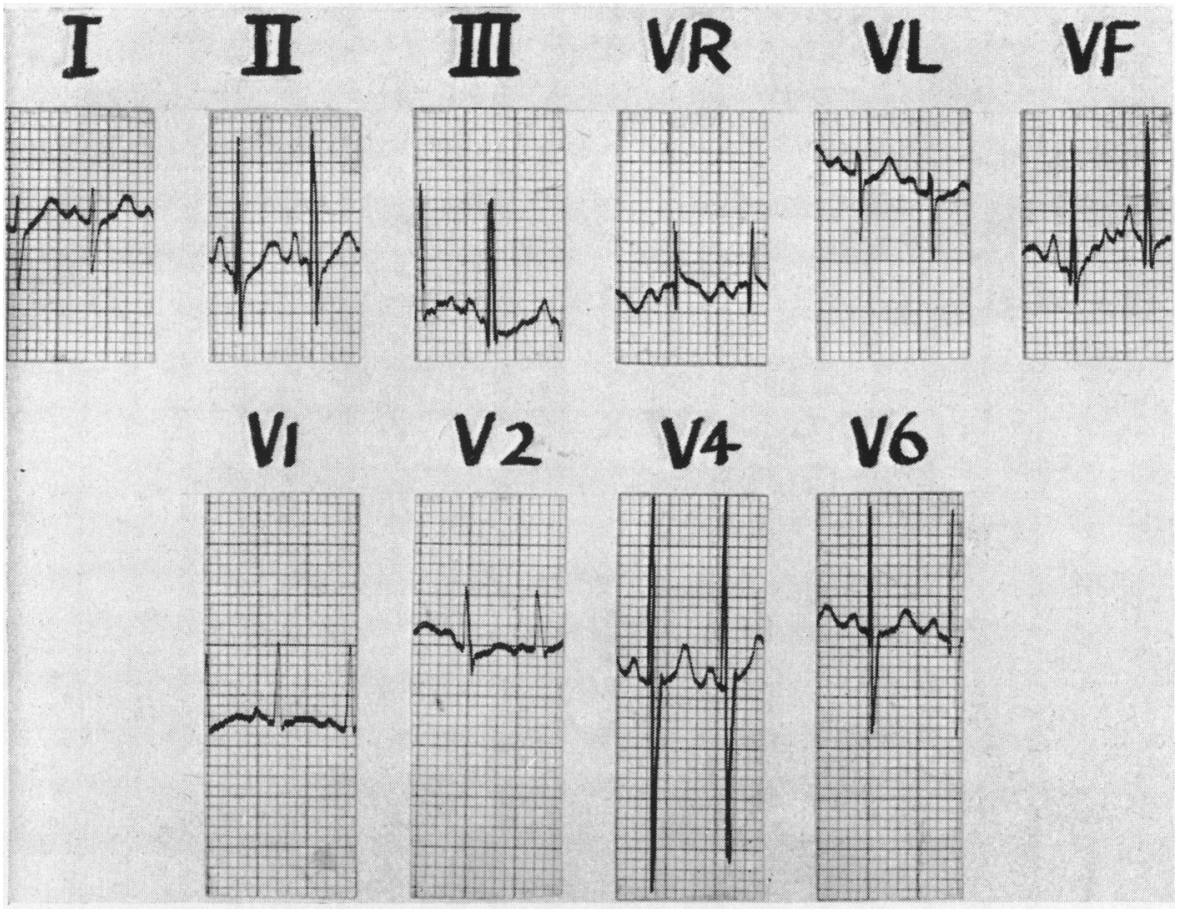

FIG. 4.-The $\mathrm{R} / \mathrm{S}$ ratio in $\mathrm{V} 1$ of 8.0 (criterion 7.0), and in aVR of 2.0 (criterion, over 1.0) together with the $3 \mathrm{~mm}$. P wave indicate a pathological degree of right ventricular preponderance. Case of atrial septal defect, aged 2 months, with moderate R.V.H. (autopsy proof).

help in diagnosis. The incidence is lower than that of 53 per cent given by Sokolow and Lyon (1949) who found it to be the most commonly encountered criterion of R.V.H.

Slurring or notching of a tall $\mathbf{R}$ wave in V1, usually near its base, is a fairly common finding in cases of congenital heart disease with R.V.H. In such cases a diagnosis of bundle-branch block would seem to be misleading since the main change present is that of ventricular hypertrophy. The vectorcardiographic work of Lasser and Grishman (1951) supports this view.

Lead $a V R$. R/Q or R/S ratios exceeding 1.0 were found in 17 cases $(65 \%)$ and denoted an abnormality in 5 in which the actual amplitude of the $R$ wave was normal. Lead aVR was abnormal in two cases where lead V1 was normal in all respects and this combination has been reported too by Goodwin (1952) and by Myers et al. (1948).

Lead $a V F$. The $\mathrm{R}$ wave was the major QRS component in 76 per cent of cases but it exceeded the normal maximum of $20 \mathrm{~mm}$. in only one.

Electrical Axis. An abnormal degree of right axis deviation was found in 16 cases $(55 \%)$ and in one it was the sole abnormality. In 5 cases the axis was negative, ranging from $-30^{\circ}$ to $-127^{\circ}$, two of these being very unusual in that it lay between $-90^{\circ}$ and $-180^{\circ}$. The occurrence of left axis deviation in R.V.H. has been particularly studied by Kroop et al. (1951) and by Lasser and Grishman (1951), who found that the determining factor was a tall $R$ wave in aVL greater than the $\mathrm{R}$ in $\mathrm{aVF}$ : this was found to be so in 4 of the 5 present cases.

Electrical Position. According to criteria of Wilson et al. (1944) the electrical position of the heart was horizontal in $16(61 \%)$, semi-horizontal in three, intermediate in one, vertical in one, and indeterminate in four. As Woods (1952) suggested, the electrical position as determined by Wilson's criteria are more in accord with the anatomical position of the heart than when determined by the criteria of Goldberger (1949). 


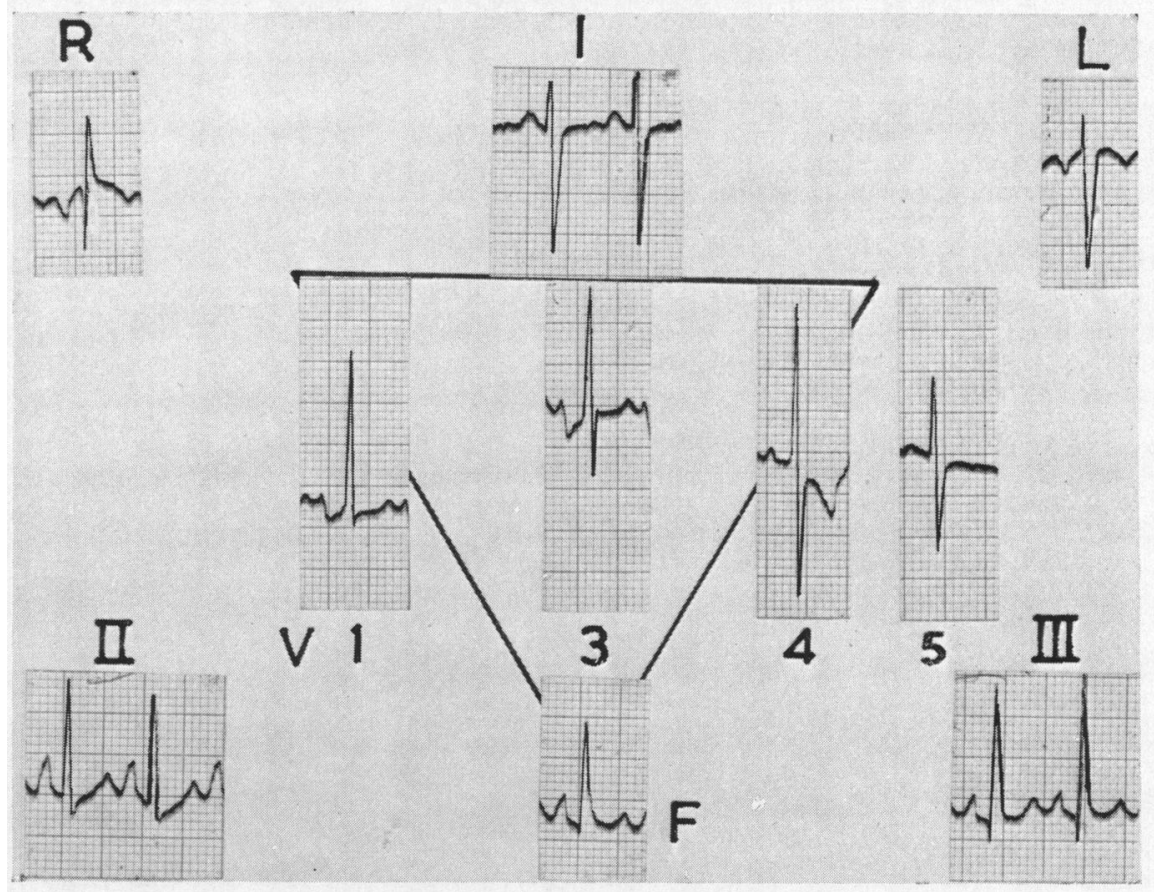

FIG. 5.-The R/S ratios in V1 of 19 (criterion 2.5 ) and in V5 of 0.8 (criterion 0.8 ) indicate right ventricular hypertrophy as does the $P$ wave of $4 \mathrm{~mm}$. (criterion $3 \mathrm{~mm}$.). Case of mitral atresia and ventricular septal defect, aged 1 year, with considerable R.V.H. (autopsy proof).

$P$ wave. Abnormally tall $\mathrm{P}$ waves were found in one or more leads in 17 cases $(57 \%)$, most frequently in leads II, aVF, and V3. The mean duration of the abnormal $P$ waves of 0.06 sec. is normal.

\section{SUMMARY}

The usual adult criteria for right ventricular hypertrophy are inapplicable in infants and young children because of the presence of physiological R.V.H. Special numerical criteria have therefore been constructed for various age groups from one month to fifteen years. Their reliability has been established by applying them to an autopsy series of lone right ventricular hypertrophy. It was found possible to differentiate pathological from physiological hypertrophy in 86 per cent of this series and to make a probable differentiation in a further 10 per cent.

The most common finding was an abnormally high $\mathrm{R} / \mathrm{S}$ ratio in V1. Under three months of age the normal and abnormal figures for this ratio have a slight overlap that may make diagnosis uncertain from this lead alone. However there is ample scope for change to a grossly abnormal pattern in V5 which thus has a particular value in the very young.

It is a pleasure to thank Dr. Arnold L. Johnson for kindly providing the facilities for this work and for his helpful suggestions and criticism. Dr. F. R. Wigglesworth and Dr. R. de Pape provided the pathological data and their help is gratefully acknowledged.

\section{REFERENCES}

Alimurung, M. M., Joseph L. G., Nadas, A. S., and Massell, B. F. (1951). Circulation, 4, 420.

Barker, J. M., and Valencia, F. (1949). Amer. Heart J., 38, 376.

Cabrera, E. and Monroy, J. R. (1956). Amer. Heart J., 43, 667. 
Goldberger, E. (1949). Unipolar Lead Electrocardiography. 2nd. ed., H. Kimpton, London.

Goodwin, J. F. (1952). Brit. Heart J., 14, 193.

Gordon, A., and Goldberg, H. (1951). Amer. Heart J., 41, 226.

Gros, G., Gordon, A., and Miller, R. (1951). Pediatrics, 8, 349.

Kroop, I. G., Steinberg, M. F., and Grishman, A. (1951). Amer. Heart J., 41, 891.

Laham, J., Gialloreto, O., and Lenegre, J. (1951). Acta Cardiol. Brux., 6, 129.

Lasser, R. P., and Grishman, A. (1951). Amer. Heart J., 41, 901.

Myers, G. B., Klein, H. A., and Stonfer, B. E. (1948). Amer. Heart J., 35, 1.

Richman, B., and Master, A. M. (1951). Amer. Heart J., 41, 687.

Schaffer, A. I. (1950). Amer. J. Dis. Child., 80, 260.

, Burstein, J., Mascia, A. V., Barenberg, P. L., and Stillman, N. S. (1950). Amer. Heart J., 39, 588.

Sokolow, M., and Lyon, T. P. (1949). Amer. Heart J., 38, 273.

, and Edgar, A. L. (1950). Amer. Heart J., 40, 232.

Switzer, J. L., and Besoain, M. (1950). Amer. J. Dis. Child., 79, 449.

Tudbury, P. B., and Atkinson, D. W. (1950). J. Pediat., 36, 466.

Veasey, L. G., and Adams, F. H. (1952). Pediatrics, 9, 395.

Wilson, F. N., Johnson, F. D., Rosenbaum, F. F., Erlanger, H., Kossmann, C. E., Hecht, H., Cotrim, N., Memezes de Olivera, R., Scarsi, D., and Barker, P. S. (1944). Amer. Heart J., 27, 19.

Woods, A. (1952). Brit. Heart J., 14, 193.

Yu, P. N. G., Joos, H. A., and Katsampes, C. P. (1951). Amer. Heart J., 41, 91.

Ziegler, R. F. (1951). Electrocardiographic Studies in Normal Infants and Children. Springfield, Charles C. Thomas. -, (1956). Amer. Heart J., 52, 533. 